\title{
Schematic concept formation: Feature measures and constraint redundancy as predictors ${ }^{1}$
}

Constraint redundancy $\left(R_{c}\right)$ was varied in order to manipulate the statistical structure of sets of patterns. Measures of pattern features and $R_{c}$ were related to the categorization by $S s$ who had experienced different types of preexposure to sets of patterns from the same stimulus domain. Both $R_{c}$ and pattern measures were related to the categories produced by $S s$ in a schematic-concept-formation (SCF) task.

This study is one in a series that was designed to integrate two different approaches to the quantitative study of visual pattern perception. The first approach, based upon information theory, assumes that the pattern perceiver is sensitive to characteristics of sets of patterns that are quantified through information metrics. A number of investigators have supported this view, and this position has been clarified and extended by Evans $(1967 \mathrm{a}, \mathrm{b})$ and his coworkers. The second approach is based upon the assumption that the $O$ encodes particular features of individual patterns, and that perceptual performance can be accounted for by quantifying those pattern aspects and constructing a model for the process whereby features are combined into a unitary response. This approach has been reviewed (Michels \& Zusne, 1965; Brown \& Owen, 1967), and a number of studies have demonstrated the predictive utility of such an analysis in this laboratory (Aiken \& Brown, 1969a, b, c; Behrman \& Brown, 1968; Brown \& Andrews, 1968; Brown \& Brumaghim, 1968; Brumaghim \& Brown, 1968; Mavrides \& Brown, 1969) and in others (e.g., Attneave, 1957; Stenson, 1968).

Earlier we argued that the $O$ is sensitive to both the properties of particular patterns and to properties of sets of patterns (Brown \& Owen, 1967). In particular, it has been argued that the stimuli for the perception of pattern are the quantities of particular features to which the $O$ is sensitive. If we view pattern as a complex attribute of multidimensional objects or events, then we may conceive of patterns as being imbedded in a multidimensional cue-dimension space (Beach, 1964a,b), where the cue dimensions are defined by the orderings of patterns with regard to their perceptually relevant features. An appropriate analysis of the properties of sets of patterns is, then, in terms of the distributions in the cue-dimension space. Based upon this conceptualization, important research questions include identifying and quantifying perceptually relevant features and constructing a model by which the $O$ combines his knowledge of the cue-dimension space into a unitary response.

In an earlier study (Mavrides \& Brown, 1969), this general conceptualization was evaluated in both a reproduction and a discrimination task. When the statistical structure of sets of patterns was controlled through the manipulation of constraint redundancy $\left(R_{c}\right)$ (Evans, 1967a, b), it was possible to account for a significant proportion of performance variance from knowledge of $R_{c}$. Superior prediction occurred, however, when performance was predicted as a linear combination of the magnitudes of pattern features. The results were interpreted as support for the notion that the effect of varying the statistical structure of sets of patterns is mediated through changes in the statistical structure of the cue-dimension space.

This study was designed to provide similar data for a categorization task that Evans (1967b) has labeled schematic concept formation (SCF) and that has been investigated in a series of studies in his laboratory (Brown \& Evans, 1969; Brown, Walker, \& Evans, 1968, 1969; Edmonds \& Mueller, 1968; Edmonds, Mueller, \& Evans, 1966; Evans, 1964; Evans \& Arnoult, 1967; Evans \& Edmonds, 1966; Ranken \& Evans, 1968).

\section{METHOD}

\section{Pattern Generation and Quantification}

The pattern generation and quantification procedures have been described in more detail elsewhere (Mavrides \& Brown, 1969). One hundred histoforms were generated ${ }^{3}$ at each of three levels of $\mathbf{R}_{\mathrm{c}}(0 \%, 40 \%, 70 \%)$, using the VARGUS 9 system (Evans \& Mueller, 1966). A single eight-column prototype was used. The histoforms were transformed into polygons according to the suggestion of Thurmond and Alluisi (1967) by mapping column heights of histoforms into radial lengths in a cricular matrix. This

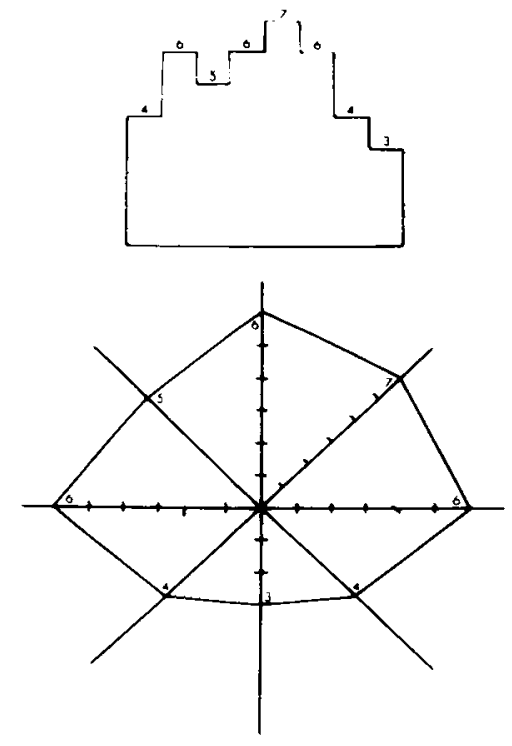

Fig. 1. Transformation from histoforms to polygon format.

operation is shown graphically in Fig. 1 for the prototype pattern.

Computer programs adjusted the area of the polygons to a constant, and 80 measures (Brown \& Owen, 1967) were computed from the coordinates in a 100 by 100 unit matrix. Since a small subset of the 80 measures have been previously found to account for performance in a variety of tasks, all subsequent analyses were based upon 7 of the 80 measures. ${ }^{4}$ Samples of the transformed polygons are shown for the three levels of $R_{c}$ in Fig. 2(a-c).

\section{Subjects}

Forty Purdue undergraduates, who were paid for their participation, served as Ss.

\section{Procedure and Design}

Eight groups of five Ss each were assigned to eight experimental conditions, which were defined by conditions of a training session and a subsequent testing session.

Six training conditions were defined on the basis of the type of patterns to which Ss were exposed. In three conditions, 40 patterns were selected randomly from the $\mathbf{R}_{\mathrm{c}}=0 \%, 40 \%$, and $70 \%$ patterns, 

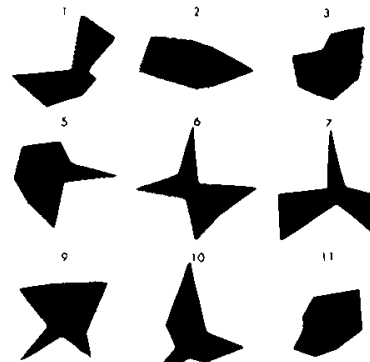

政

고
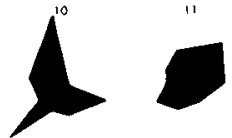

.
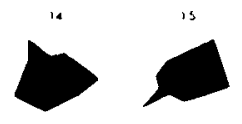

$L$
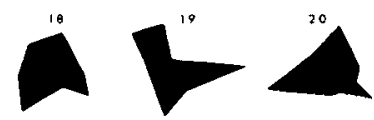

O. CONSTRAINT IRANDOMI

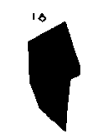

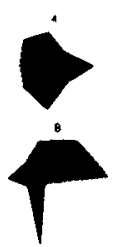
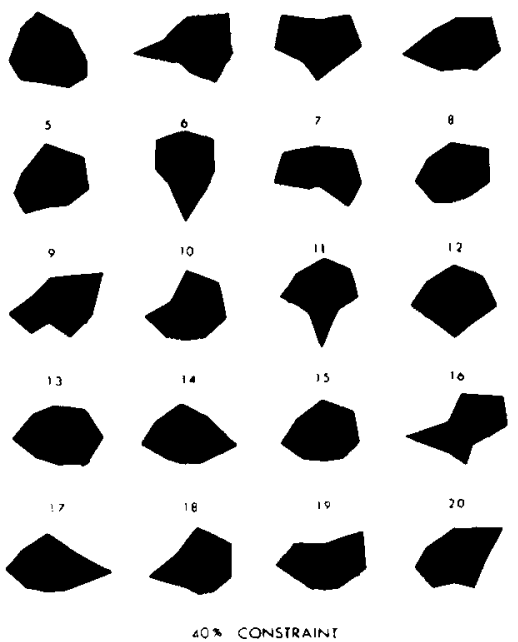

40 CONSTRAIN
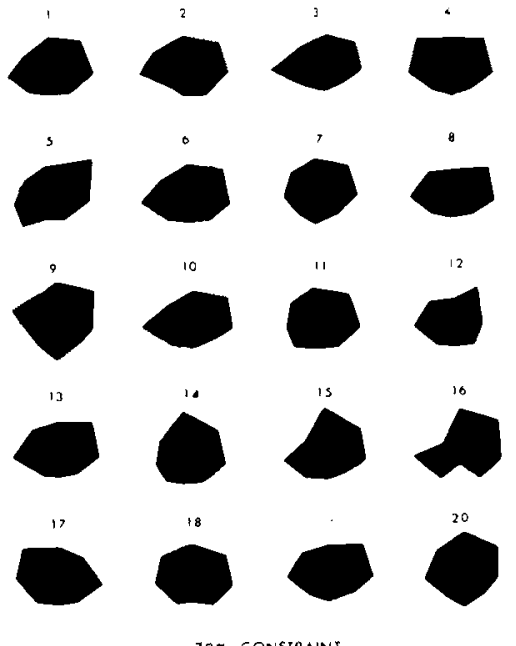

70* CONSTPAINF

Fig. 2. Sample forms with $R_{c}=0 \%$ (a), $40 \%$ (b), and $70 \%$ (c). were selected randomly from the $R_{c}=0 \%$ patterns, and the other 20 patterns were selected randomly from the $\mathrm{R}_{\mathrm{c}}=40 \%$ and $R_{c}=70 \%$ patterns, respectively. A sixth condition was defined for $10 \mathrm{Ss}$ by the absence of preexposure to patterns prior to the testing session. The $\mathrm{Ss}$ in the five groups viewed 40 slides projected on a screen in a random sequence. Thirty-seven of the patterns were projected for a $5-\mathrm{sec}$ duration, and the remaining three, randomly selected, were presented for only $2 \mathrm{sec}$. Ss were instructed to detect the short-duration patterns and to record their numbers on a response sheet. The task was designed to insure attention to the patterns during the pretraining session.

The test phase of the experiment was designed to assess the ability of Ss to detect the presence of a schema representing a set of patterns and to determine the pattern features that provide the basis for assigning patterns accurately to the schema class. Immediately after the pretraining session, eight groups of five $S s$ each were formed. For each group, 41 randomly selected $R_{c}=0 \%$ patterns and 39 schematic patterns $\left(\mathbf{R}_{\mathrm{c}}=40 \%\right.$ or $\left.70 \%\right)$ were presented for $5 \mathrm{sec}$ each in a random sequence. Patterns were selected randomly, with the restriction that none of the patterns were the same as those used in the training conditions. Ss were instructed that the patterns belonged to two equal-sized groups ${ }^{5}$ that they should jdentify as A or B and to which they should assign each pattern. The eight groups were formed from the training groups. The group of 10 Ss who were preexposed to $R_{c}=0 \%$ patterns were divided randomly into two groups of five each and were tested with respectively. In two conditions, 20 patterns
$R_{c}=40 \%$ and $R_{c}=70 \%$ patterns, respectively. The two groups preexposed to $\mathrm{R}_{\mathrm{c}}=40 \%$ and $\mathrm{R}_{\mathrm{c}}=70 \%$ patterns were tested with $\mathrm{R}_{\mathrm{c}}=40 \%$ and $\mathrm{R}_{\mathrm{c}}=70 \%$ patterns, respectively. The two groups with mixed exposure to $R_{c}=0 \%$ and $R_{c}=40 \%$ and to mixed exposure to $R_{c}=0 \%$ and $\mathbf{R}_{\mathbf{c}}=40 \%$ patterns were tested with $\mathrm{R}_{\mathrm{c}}=40 \%$ and $\mathrm{R}_{\mathrm{c}}=70 \%$ patterns, respectively. Ten Ss with no preexposure were assigned randomly to two groups of five Ss each and were tested with $R_{c}=40 \%$ and $\mathrm{R}_{\mathrm{c}}=70 \%$ patterns, respectively. The task, then, for each group of Ss was to detect the presence of a set of schematic patterns $\left(R_{c}=40 \%\right.$ or $\left.70 \%\right)$ in the presence of an equal number of randomly generated patterns $\left(\mathrm{R}_{\mathrm{c}}=0 \%\right)$.

\section{RESULTS}

Since assignment of patterns to classes (A or B) was arbitrary, Ss were asked to describe their categories in writing, and

Table 1

Chi Square Values and the Associated Phi Coefficient for Analyses of Twenty-Trial Blocks in Each Experimental Condition

\begin{tabular}{|c|c|c|c|c|c|c|c|c|c|}
\hline \multirow[b]{3}{*}{ Trials } & & \multicolumn{8}{|c|}{ Constraint of Test Stimuli } \\
\hline & & \multicolumn{4}{|c|}{$\begin{array}{c}40 \% \\
\text { Training Methods* }\end{array}$} & \multicolumn{4}{|c|}{$\begin{array}{c}70 \% \\
\text { Training Methods }\end{array}$} \\
\hline & & 1 & 2 & 3 & 4 & 1 & 2 & 3 & 4 \\
\hline $1-20$ & $\begin{array}{l}\text { Chi Square } \\
\text { Phi }\end{array}$ & $\begin{array}{r}5.05 \\
.50\end{array}$ & $\begin{array}{r}10.48 \\
.73\end{array}$ & $\begin{array}{l}1.82^{* *} \\
.30\end{array}$ & $\begin{array}{r}7.01 \\
.59\end{array}$ & $\begin{array}{r}20.00 \\
1.00\end{array}$ & $\begin{array}{r}16.26 \\
.90\end{array}$ & $\begin{array}{r}20.00 \\
1.00\end{array}$ & $\begin{array}{r}13.39 \\
.82\end{array}$ \\
\hline $21-40$ & $\begin{array}{l}\text { Chi Square } \\
\text { Phi }\end{array}$ & $\begin{array}{r}5.05 \\
.50\end{array}$ & $\begin{array}{r}16.36 \\
.90\end{array}$ & $\begin{array}{r}7.50 \\
.61\end{array}$ & $\begin{array}{r}13.33 \\
.82\end{array}$ & $\begin{array}{r}10.77 \\
.73\end{array}$ & $\begin{array}{r}13.33 \\
.82\end{array}$ & $\begin{array}{r}16.36 \\
.90\end{array}$ & $\begin{array}{r}16.36 \\
.90\end{array}$ \\
\hline $41-60$ & $\begin{array}{l}\text { Chi Square } \\
\text { Phi }\end{array}$ & $\begin{array}{r}16.30 \\
.90\end{array}$ & $\begin{array}{r}9.73 \\
.70\end{array}$ & $\begin{array}{r}9.73 \\
.70\end{array}$ & $\begin{array}{r}8.65 \\
.66\end{array}$ & $\begin{array}{r}12.54 \\
.79\end{array}$ & $\begin{array}{r}8.65 \\
.66\end{array}$ & $\begin{array}{r}16.30 \\
.90\end{array}$ & $\begin{array}{r}12.86 \\
.80\end{array}$ \\
\hline $61-80$ & $\begin{array}{l}\text { Chi Square } \\
\text { Phi }\end{array}$ & $\begin{array}{l}3.03 * * \\
.41 \\
\end{array}$ & $\begin{array}{r}6.71 \\
.58 \\
\end{array}$ & $\begin{array}{r}16.30 \\
.90 \\
\end{array}$ & $\begin{array}{r}13.33 \\
.82 \\
\end{array}$ & $\begin{array}{r}12.54 \\
.79 \\
\end{array}$ & $\begin{array}{r}13.33 \\
.82 \\
\end{array}$ & $\begin{array}{r}12.86 \\
.80 \\
\end{array}$ & $\begin{array}{r}13.33 \\
.82 \\
\end{array}$ \\
\hline
\end{tabular}

* Training Methods numbered as follows: (1) Schematic plus random; (2) Schematic; (3) Random; (4) None

${ }_{* *}^{*} p>.05 ;$ for all other cases $p \leqslant .05$ (degrees of freedom $=1$ ) from their descriptions it was possible to dentify the category of their sort that corresponded to the schematic category. All analyses were based upon the modal response, i.e., the categorization of each pattern given by most Ss.

In order to assess the extent to which $\mathrm{SCF}$ occurred during the training and test 80 test trials were divided into four blocks of 20 trials each for each group of Ss. For each condition and each trial de degree of association between the actual origin ( $R_{c}$ level) of the patterns and the modal-assigned category was evaluated with chi-square tests and phi coefficients. These statistics are shown in . Several points should be apparent rom Table 1. First, it is clear that Ss were ble to discriminate schematic patterns accurately under both $R_{c}$ levels and all conditions of pretraining. Moreover, this ability was present during the first block of 20 trials under all but one condition. It is 
Table 2

Intercorrelations Among the Seven Physical Measures for the 80 Sorting Forms at $40 \%$ Constraint and Between Measures and the Classification Dichotomy $\left(R_{c}=0 \%\right.$ vs $\left.R_{c}=40 \%\right)$

\begin{tabular}{|c|c|c|c|c|c|c|c|c|}
\hline & \multicolumn{8}{|c|}{ Measures* } \\
\hline & 1 & 2 & 3 & 4 & 5 & 6 & 7 & 0 \\
\hline $\begin{array}{l}1 \\
2 \\
3 \\
4 \\
5 \\
6 \\
7\end{array}$ & - & $\begin{array}{c}-.12 \\
-\end{array}$ & $\begin{array}{c}-.10 \\
-.10 \\
-\end{array}$ & $\begin{array}{r}.77 \\
.11 \\
-.27 \\
-\end{array}$ & $\begin{array}{r}.41 \\
.19 \\
-.33 \\
.79 \\
-\end{array}$ & $\begin{array}{r}.73 \\
-.22 \\
-.07 \\
.69 \\
.55 \\
-\end{array}$ & $\begin{array}{r}.76 \\
.07 \\
-.15 \\
.76 \\
.45 \\
.54 \\
-\end{array}$ & $\begin{array}{r}-.68 \\
.18 \\
.26 \\
.62 \\
-.45 \\
-.71 \\
-.67\end{array}$ \\
\hline
\end{tabular}

* Measures numbered as in Footnote 3. Column 0 is the original classification dichoromy $\left(R_{c}=0 \%\right.$ vs $\left.R_{c}=40 \%\right)$.

Table 3

Intercorrelations Among the Seven Physical Measures for the 80 Sorting Forms at $\mathbf{7 0 \%}$ Constraint and Between Measures and the Classification Dichotomy $\left(R_{c}=0 \%\right.$ vs $\left.R_{c}=70 \%\right)$

\begin{tabular}{|c|c|c|c|c|c|c|c|c|}
\hline & \multicolumn{8}{|c|}{ Measures } \\
\hline & 1 & 2 & 3 & 4 & 5 & 6 & 7 & 0 \\
\hline 1 & - & .04 & -.13 & -.07 & .02 & -.09 & .11 & -.91 \\
\hline 2 & & - & .72 & .79 & .81 & .48 & -.73 & .25 \\
\hline 3 & & & - & .95 & .93 & .41 & -.87 & .26 \\
\hline 4 & & & & - & .97 & .48 & -.91 & .87 \\
\hline 5 & & & & & - & .40 & -.93 & -.74 \\
\hline 6 & & & & & & - & -.30 & -.70 \\
\hline 7 & & & & & & & - & -.94 \\
\hline
\end{tabular}

also apparent that, under most conditions, the ability to do this is related to the level of constraint redundancy, i.e., the association was generally higher for $\mathbf{R}_{\mathrm{c}}=70 \%$ than for $\mathbf{R}_{\mathrm{c}}=40 \%$ throughout testing and especially during the first trial block.

While these results confirm that SCF occurs under a variety of conditions, extend previous results to include polygons, and demonstrate that SCF is related to the statistical structure of the set of patterns $\left(R_{c}\right)$, our primary interest lay in determining the extent to which categorization could be predicted from knowledge of the pattern features. To investigate this question, the linear discriminant function (LDF) was used as a method of evaluating whether Ss' categorizations were a reliable linear function of pattern features. The LDF has been discussed as both a data analysis technique and as a model for the perceiver (e.g., Hake \& Rodwan, 1966; Rodwan \& Hake, 1964) and offers a number of advantages for the present problem. If we view the sets of patterns as points in a seven-space defined by the measures, we may write the discriminant function that describes the best possible linear combination of the pattern measures that will assign the patterns to their correct $R_{c}$ level. The discriminant weights assess the relevance of each pattern measure to class membership, a distance measure (Mahalanobis $\mathrm{D}^{2}$ ) provides the distance between multidimensional means for the sets of patterns, and the number of patterns that the LDF misclassifies provides another index of the extent to which a linear $O$ can discriminate class membership accurately when he is given
Table 4

Summary of LDF for All Conditions

\begin{tabular}{|c|c|c|c|c|c|c|c|c|c|c|}
\hline \multirow{2}{*}{$\begin{array}{l}\text { Training } \\
\text { Method: }\end{array}$} & \multicolumn{5}{|c|}{$70 \%$ Constraint } & \multicolumn{5}{|c|}{$40 \%$ Constraint } \\
\hline & 1 & 2 & 3 & 4 & Model & 1 & 2 & 3 & 4 & Model \\
\hline \multicolumn{11}{|l|}{ Measure } \\
\hline 1 & -.23 & -.23 & -.14 & -.18 & -.22 & -.21 & -.08 & -.09 & -.09 & -.11 \\
\hline 2 & -.03 & -.05 & -.23 & -.08 & .09 & .11 & .07 & .05 & .04 & .03 \\
\hline 3 & .03 & .12 & .13 & .27 & .13 & .01 & .02 & .04 & .02 & .12 \\
\hline 4 & .57 & .60 & .01 & -.55 & .62 & .21 & .35 & .16 & .10 & .37 \\
\hline 5 & -.31 & -.29 & .06 & -.51 & -.42 & -.23 & -.24 & -.14 & -.11 & -.25 \\
\hline 6 & -.22 & -.23 & .00 & .10 & -.30 & -.02 & -.13 & -.06 & .03 & -.23 \\
\hline 7 & -.26 & -.30 & .06 & .00 & -.37 & -.08 & -.23 & -.13 & -.06 & -.28 \\
\hline $\mathrm{D}^{2}$ & 10.04 & 10.34 & 3.76 & 12.76 & 16.86 & 6.19 & 6.48 & 3.15 & 3.13 & 9.52 \\
\hline$F^{*}$ & 25.89 & 27.29 & 9.79 & 33.28 & 44.44 & 6.07 & 16.43 & 8.17 & 8.24 & 25.10 \\
\hline \multicolumn{11}{|c|}{ Overlapping } \\
\hline Cases & 5 & 5 & 12 & 3 & 2 & 10 & 10 & 12 & 12 & 8 \\
\hline
\end{tabular}

$p \leqslant .01$ the measures and behaves in an ideal linear fashion.

The correlations (Pearson product moment) among measures and between measures and class membership (point biserial) for discriminating between $R_{c}=0 \%$ and $R_{c}=40 \%$ (Table 2) and between $\mathbf{R}_{c}=0 \%$ and $\mathbf{R}_{c}=70 \%$ (Table 3) are shown. It is clear that manipulating $\mathbf{R}_{c}$ levels modifies the statistical structure of the measure space (correlations among measures are different in the two tables), and that some of the measures are linearly related to class membership at both levels of $\mathbf{R}_{\mathrm{c}}$, with the degree of association between measures and $R_{c}$ increasing from $\mathbf{R}_{\mathrm{c}}=40 \%$ to $\mathbf{R}_{\mathrm{c}}=70 \%$, as expected.

Table 4 summarizes the LDF results under all conditions. The two columns labeled "Model" refer to the LDF for assigning patterns to the categories based upon the method of generation, i.e., $\mathbf{R}_{\mathbf{c}}=0 \%$ vs $\mathbf{R}_{\mathrm{c}}=40 \%$ and $\mathbf{R}_{\mathrm{c}}=0 \%$ vs $\mathbf{R}_{c}=70 \%$, and provide the criteria against which Ss may be compared. The $D^{2}$ statistic is the square of the vector of differences between means for the two groups of patterns in the measure space and, like $\mathrm{d}^{\prime}$ of SDT, may be viewed as a discrimination measure between classes of patterns. Clearly, the discrimination between clusters of patterns in the measure space increases with $R_{c}$. The $F$ statistic tests the significance of the difference between the multidimensional means in the measure space with $k$ and $n_{1}+n_{2}-k-1 d f$, where $k$ is the dimensionality of the measure space and $n_{1}$ and $n_{2}$ are the numbers of patterns in the two classes. With 7 and $72 \mathrm{df}$, both model equations perform as reliable linear classifiers in reconstituting the original pattern classes $(p \leqslant .001)$. This same conclusion is supported by noting that only eight and two patterns are misclassified for $R_{c}=40 \%$ and $70 \%$ patterns, respectively. The discriminant weights to achieve maximal linear performance are given as entries in the table. In both equations, only Measures 2 and 3 are ignored by the LDF, while most weight is given to the cluster of Measures 4-7. This is logical in view of the fact that the prototype pattern resembled a regular polygon, and this cluster of intercorrelated measures assesses the extent to which the area and perimeter are concentrated compactly around the area center of gravity; Measure 1 has previously been labeled a measure of "jaggedness," while Measures 2 and 3 assess the degree of skew of the area and perimeter with regard to the $X$ and $Y$ axes, respectively, and had little validity with this set of patterns.

In general, it is worth noting that, under all conditions, Ss were able to achieve a 
level of discrimination between classes that was statistically significant $(p \leqslant .01)$, and that discrimination was better (except for those Ss preexposed to random patterns) with the more constrained patterns. We also know (Table 1) that the discriminations made by the $S s$ were related to the $R_{c}$ levels. If we restrict our attention to the data involving the $\mathrm{R}_{\mathrm{c}}=40 \%$ patterns, it is clear that $\mathrm{Ss}$ categorized patterns almost as well as the model equation, and that the small difference in accuracy that occurred as a function of the type of preexposure favored those Ss who previously viewed schematic patterns (Conditions 1 and 2). We cannot infer from these data, however, that the Ss made their class distinction on the basis of this particular set of pattern measures. This can be inferred only from the similarity of their discriminant weights to those in the model equation. In that regard, those Ss who were preexposed to the schematic patterns seem to have "matched" the model equation most closely. Under other conditions, only Measures 4 and 5 were consistently weighted. For the $\mathbf{R}_{\mathrm{c}}=70 \%$ patterns, discrimination was near ideal under three of the conditions, and the equations more closely matched the model weighting scheme, especially for those Ss who had viewed schematic patterns. That Ss who had been preexposed only to the random $\left(R_{c}=0 \%\right)$ patterns performed poorly, even when compared to Ss who had not previously seen patterns, is difficult to explain. It is reasonable to assume that this experience may have led them to attend to an invalid set of pattern measures. That this may be true is suggested by the large weight assigned to Measure 2.

\section{DISCUSSION}

Following Attneave (1957), Oldfield (1954), and Woodworth (1938), Evans has supported the view that efficient information processing may involve encoding the schematic aspects of stimuli (1967b). Schema are considered to be abstracted as a common set of characteristics that describe a collection of stimuli, or schema family, and SCF is the process whereby Ss develop the ability to discriminate among schema families. Numerous studies have demonstrated the existence of SCF and have examined the conditions for its occurrence using histoforms as patterns and $R_{c}$ as an index of schematic definition.

The present data extend previous results to indicate that SCF occurs with polygons over a variety of conditions of preexposure. Moreover, the data support the conclusion that $\mathrm{Ss}$ are sensitive to the statistical structure of sets of patterns in that performance varied with levels of $R_{c}$. More importantly, however, the data also demonstrate the feasibility of quantifying the set of pattern characteristics that defines the existence of a schema family as a collection of points in a measure space, an approach that provides for describing both individual instances of stimulation and the population of which the instances are the elements. Like discrimination difficulty and the accuracy of pattern reproduction (Mavrides \& Brown, 1969), it is possible to describe classification behavior as a linear function of pattern features with a reasonable degree of accuracy.

\section{REFERENCES}

AIKEN, L. S., \& BROWN, D. R. Visual form perception: Congruence among spatial configurations. Perception \& Psychophysics, 1969a, 5, 155-160.

AIKEN, L. S., \& BROWN, D. R. A spatial analysis of the discriminability of forms in noise. Perception \& Psychophysics, 1969b, 5, 171-175.

AIKEN, L. S., \& BROWN, D. R. Visual form perception: Task demands and congruence among spatial solutions. Psychonomic Science, $1969 c, 15,219-220$.

ATTNEAVE, F. Transfer of experience with a class-schema to identification-learning of patterns and shapes. Journal of Experimental Psychology, 1957, 54, 81-88.

$B E A C H, L$. R. Cue probabilism and inference behavior. Psychological Monographs, 1964a, 78(Whole No. 582).

BEACH, L. R. Recognition, assimilation, identification of objects. Psychological Monographs, 1964b, 78(Whole No. 583).

BEHRMAN, B. W., \& BROWN, D. R. Multidimensional scaling of form: A psychophysical analysis. Perception \& Psychophysics, 1968, 4, 19-25.

BROWN, B. R., \& EVANS, S. H. Perceptual learning in pattern discrimination tasks with two and three schema categories. Psychonomic Science. 1969, 15, 101-103.

BROWN, B. R., WALKER, D. W., \& EVANS, S. H. Schematic concept formation as a function of constraint redundancy and knowledge of results. Psychonomic Science, 1968, 11, 75-76.

BROWN, D. R., \& ANDREWS, M. H. Visual form discrimination: Multidimensional analyses. Perception \& Psychophysics, 1968, 3, 401-406.

BROWN, D. R., \& BRUMAGHIM, S. H. Perceptual equivalence, pattern perception, and multidimensional methods. Perception \& Psychophysics, 1968, 4, 253-256.

BROWN, D. R., \& OWEN, D. H. The metrics of visual form: Methodological dyspepsia. Psychological Bulletin, 1967, 68, 243-259.

BRUMAGHIM, S. H., \& BROWN, D. R Perceptual equivalence between visual and tactual pattern perception: An anchoring study. Perception \& Psychophysics, 1968, 4 175-179.

EDMONDS, E. M., \& EVANS, S. H. Prediction of schema learning by linear regression. Psychonomic Science, 1966a, 5, 457-458.

EDMONDS, E. M., \& EVANS, S. H. Schema learning without a prototype. Psychonomic Science, 1966b, 5, 247-248.
EDMONDS, E. M., \& MUELLER, M. R. The role of schemata in perceptual learning. Psychonomic Science, 1967, 8, 239-240.

EDMONDS, E. M., \& MUELLER, M. R. Effects of incidental training and reinforcement on mixed schema learning. Psychonomic Science, $1968,10,75-76$.

EDMONDS, E. M., MUELLER, M. R., \& EVANS, S. H. Effects of knowledge of results on mixed schema discrimination. Psychonomic Science, 1966, 6, 377-378.

EVANS, S. H. A model for perceptual category formation. Unpublished doctoral dissertation, Texas Christian University, 1964.

EVANS, S. H. Redundancy as a variable in pattern perception. Psychological Bulletin, 1967a, 67, 104-113.

EVANS, S. H. A brief statement of schema theory. Psychonomic Science, 1967b, 8, 87-88.

EVANS, S. H., \& ARNOULT, M. D. Schematic concept formation: Demonstration in a free sorting task. Psychonomic Science, 1967, 9, 221-222.

EVANS, S. H., \& EDMONDS, E. M. Schema discrimination as a function of training. Psychonomic Science, 1966, 5, 303-304.

EVANS, S. H., \& MUELLER, M. R. VARGUS 9: Computer stimuli for schema research. Psychonomic Science, 1966, 6, 511-512.

HAKE, H. W., \& RODWAN, A. S. Perception and re cognition. In J. B. Sidowski (Ed.), Experimental methods and instrumentation in psychology. New York: McGraw-Hill, 1966. Pp. 331-381.

MAVRIDES, C., \& BROWN, D. R. Discrimination and reproduction of patterns: Feature measures and constraint redundancy as predictors. Perception \& Psychophysics, $1969,0,000-000$.

MICHELS, K. M., \& ZUSNE, L. Metrics of visual form. Psychological Bulletin, 1965, 63, 74-86.

OLDFIELD, R. C. Memory mechanisms and the theory of schemata. British Journal of Psychology, 1954, 45, 14-23.

RANKIN, W. C., \& EVANS, S. H. Facilitation of schematic concept formation as a function of two within-schema pre-training modes. Psychonomic Science, 1968, 13, 325-326.

RODWAN, A. S., \& HAKE, H. W. The discriminant function as a model in perception. American Journal of Psychology, $1964,77,380-392$.

STENSON, H. H. The psychophysical dimensions of similarity among random shapes. Perception \& Psychophysics, 1968, 3, 201-214.

THURMOND, J. B., \& ALLUISI, E. A. An extension of the information deductive analysis of form. Psychonomic Science, 1967 7, 157-158.'

WOODWGRTH, R. S. Experimental psychology.

New York: Holt, 1938.

\section{NOTES}

1. This research was supported by Research Grant HD-00909 from the National Institute of Child Health and Human Development.

2. Address: Department of Psychology, Purdue University, Lafayette, Indiana 47907.

3. We gratefully acknowledge the assistance of Dr. Selby Evans, Texas Christian University, who provided these patterns under a program of research supported in part by a Department of Defense Project THEMIS, Contract No. DAADOS-68-C-D176.

4. Measures of patterns used were (for more detailed information, see Brown \& Owen, 1967): (1) Variance of interior angles. This measure is the second central moment of the size, in degrees, of all interior angles of the polygons and 
perceptually reflects the degree of "jaggedness" of the pattem. (2) Mean of the $X$ coordinates. This measures skewness of the area with regard to the $X$ axis. (3) Mean of the $Y$ coordinates. A measure of skewness of area with regard to the $Y$ axis, (4) Second moment of the deviation of side length from that of a regular polygon with the same area. Perceptually, this measures the combined effects of dispersion of area and of variability of angle sizes. (5) Variance of side lengths. (6) Largest radial length. This is the length of the longest radius from the area center of gravity to the perimeter of the pattern. It reflects "elongation." (7) Perimeter length.
Perimeter length reflects both "jaggedness" and dispersion of area.

5. It was intended that there be $\mathbf{4 0}$ patterns in each class, but an error resulted in unequal class sizes with 40,39 , and 39 patterns for $R_{c}=0 \%$, $40 \%$, and $70 \%$, respectively.

(Accepted for publication June 12, 1969.) 